Open Access

No. 32, September 2021, pp.1-18

DOI: http://doi.org/10.52716/jprs.v11i3.529

\title{
Biodiesel Production using Synthesized HY Zeolite Catalyst
}

\author{
Dr. Ban A. Al-Tabbakh*, Sattar J. Hussein, Zena A. Hadi \\ Refining \& Gas Research Department, PRDC -Iraqi Ministry of Oil \\ "Corresponding Author E-mail: dr.banaltabbakh@gmail.com \\ E-mail: sattarjaleel@yahoo.com
}

Received 24/1/2021, Accepted 3/6/2021, Published 19/9/2021

c) (i) This work is licensed under a Creative Commons Attribution 4.0 International License.

\section{$\underline{\text { Abstract }}$}

Biodiesel was produced using oleic acid esterification and transesterification of the sunflower oil methods. Many different factors affecting production procedures were studied such as reaction temperature, the molar ratio of ethanol to oil, reaction time and concentration of HY catalyst.

Different techniques such as TGA, FTIR and Mass spectroscopy were used to syntheses biodiesel. Results showed that $78 \%$ of oleic acid maximum conversion was obtained at a temperature of $70^{\circ} \mathrm{C}$ with molar ratio $12: 1$ ethanol: oil with 5 wt.\% catalysts at $90 \mathrm{~min}$ reaction time, while for sunflower oil conversion of $98 \%$ at $200 \mathrm{oC}$ with 5 weight ratio of ethanol: oil at a time of $3 \mathrm{~h}$ was successfully obtained.

Keywords: Biodiesel, Esterification, Transesterification, Oleic Acid, HY zeolite..

\section{تحضير الوقود الحيوي باستخدام عامل مساعد غير متجانس نوع}

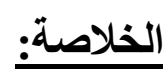

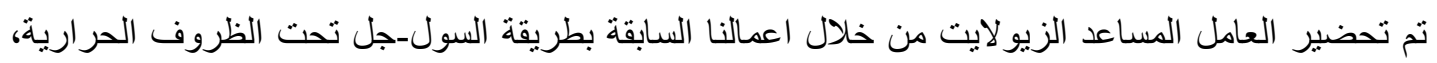

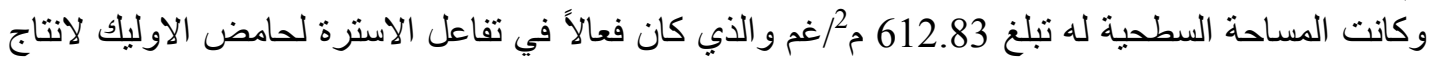

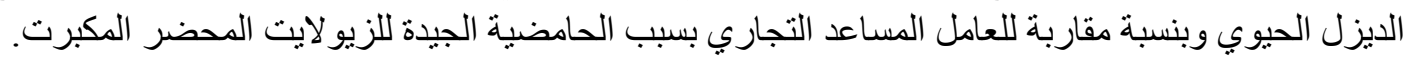

تم تحضير الوقود الحيوي باستخدام طرق مختلفة الطريقة الاولى تفاعل استرة حامض الاوليك و الطريقة الثانية

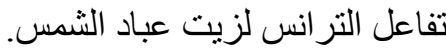

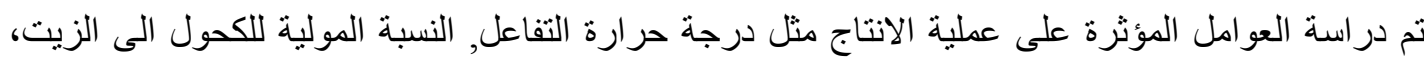

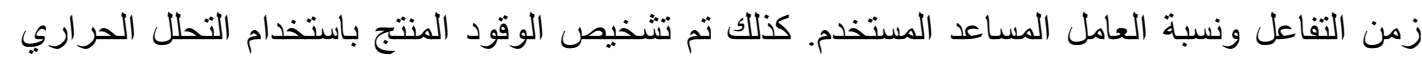
كانت اعلى نسبة تحول متحققة لحامض الاوليك 


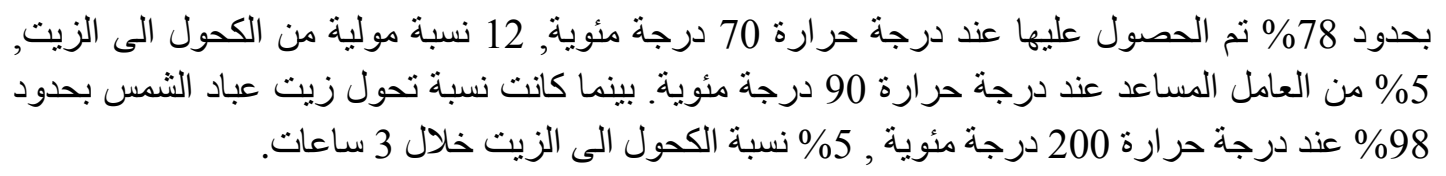

\section{Introduction:}

Biodiesel is the fuel that attracted much attention and support as more renewable and potential cleaner fuel for diesel engines, producing less air pollution compared with conventional petroleum diesel. Biodiesel can be produced from numerous biological materials, including vegetable oils and waste fats [1]. Transesterification process is the most common way of producing biodiesel where a pure triglyceride is converted into fatty methyl or ethyl ester and glycerol [2].

$$
\begin{aligned}
& \mathrm{CH}_{2}-\mathrm{OOC}-\mathrm{R}_{1} \quad \mathrm{R}_{1}-\mathrm{COO}-\mathrm{R} \quad \mathrm{CH}_{2}-\mathrm{OH} \\
& \mathrm{CH}-\mathrm{OOC}-\mathrm{R} 2+3 \mathrm{ROH} \Longleftrightarrow \mathrm{R}_{2}-\mathrm{COO}-\mathrm{R}+\mathrm{CH}-\mathrm{OH} \\
& \mathrm{CH}_{2}-\mathrm{OOC}-\mathrm{R}_{3} \quad \mathrm{R} 3-\mathrm{COO}-\mathrm{R} \quad \mathrm{CH} 2-\mathrm{OH}
\end{aligned}
$$

\section{Triglycerides Alcohol Catalyst Esters Glyceride}

Heterogeneous catalysts have been used due to their ease of separation from reaction stream, corrosion reduction and reusability. The objective of the research is firstly to investigate the activity of the synthesized HY catalyst for esterification of oleic acid to produce biodiesel under different reaction conditions (reaction time, temperature, catalytic ratio \& alcohol/oil ratio). Secondly, transesterification of treated sunflower oil to produce biodiesel under various reaction conditions (reaction temperature and time). Zeolites have been used as catalysts to convert high free fatty acid oils to FAME. A good conversion of oil into biodiesel was observed at the time between 10 minutes and 50 minutes in the basic and acidic form of zeolites, such as $\mathrm{NaY}$ zeolites, while the negative influence of water resulted in low conversion [3]. Zeolite type $\mathrm{Y}$ was prepared from Iraqi kaolin with a final Si / Al ratio of 3.1 and used in oleic acid esterification as a catalyst. A variety of parameters such as molar ratio, temperature and mass load catalyst have been tested. It was observed that $70{ }^{\circ} \mathrm{C}$, loading $5 \mathrm{wt} \%$ and $6: 1$ ethanol to oleic acid ratio fixed as the best reaction conditions. The conversion by zeolite catalyst was $85 \%$ after 60 min. Although the highest value was $76 \%$ for the commercial sample of HY zeolite. 
They found that a low zeolite content of $\mathrm{Si} / \mathrm{Al}$ was the most appropriate for use in the esterification process. [4]

\section{Experimental work}

\subsection{Materials}

Table (1) Materials list of materials supplier and purity

\begin{tabular}{|l|l|l|l|l|}
\hline Chemicals & Formula & $\begin{array}{l}\text { Molecular } \\
\text { weight g/gmol }\end{array}$ & Purity \% & Supplier \\
\hline Sunflower oil & $\begin{array}{l}\mathrm{C}_{16} \mathrm{H}_{32} \mathrm{O}_{2} \\
\mathrm{C}_{18} \mathrm{H}_{32} \mathrm{O}_{2} \\
\mathrm{C}_{18} \mathrm{H}_{34} \mathrm{O}_{2} \\
\mathrm{C}_{18} \mathrm{H}_{36} \mathrm{O}_{2}\end{array}$ & \multicolumn{1}{|c|}{876.16} & - & $\begin{array}{l}\text { Local } \\
\text { market }\end{array}$ \\
\hline Ethanol & $\mathrm{C}_{2} \mathrm{H}_{5} \mathrm{OH}$ & 46.07 & 99.8 & Scharlau \\
\hline Oleic Acid & $\mathrm{C}_{18} \mathrm{H}_{34} \mathrm{O}_{2}$ & 282.47 & 99 & Sigma \\
\hline Phenolphthalein & $\mathrm{C}_{20} \mathrm{H}_{14} \mathrm{O}_{3}$ & 318.32 & 99 & Sigma \\
\hline
\end{tabular}

\subsection{Catalyst properties:}

2.2.1 Synthesized HY zeolite prepared according to our previous work [5] having the properties listed in Table (2).

Table (2) properties of the prepared HY zeolite

\begin{tabular}{|l|l|}
\hline property & value \\
\hline $\mathrm{Al}_{2} \mathrm{O}_{3}$ wt\% & 57.96 \\
\hline $\mathrm{SiO}_{2} \quad \mathrm{wt} \%$ & 19.01 \\
\hline $\mathrm{Al}_{2} \mathrm{O}_{3} / \mathrm{SiO}_{2}$ Molar ratio & 5.2 \\
\hline $\begin{array}{l}\mathrm{BET} \\
\text { surface area m}\end{array} / \mathrm{g}$ & 612.83 \\
\hline
\end{tabular}

\subsubsection{Esterification reaction of Oleic acid}

The esterification reaction of Oleic acid and ethanol was performed in $500 \mathrm{ml}$ batch reactor under total reflux condition. It was supplied with a heating magnetic stirrer. The required catalyst amount was subjected to drying at $120 \mathrm{oC}$ for a period of $2 \mathrm{~h}$. while $50 \mathrm{ml}$ or about (44.75 g) of the oleic acid with different ethanol to oil weight ratios including $(3,6,9$ and 12$)$ at a reaction temperature of $70 \mathrm{oC}$ at an interval time 
of $15 \mathrm{~min}$. $5 \mathrm{ml}$ - samples were withdrawn from the reaction vessel- which was centrifuged for $10 \mathrm{~min}$ at $3000 \mathrm{rpm}$ to separate the HY catalyst from the liquid mixture. Acid value (AV) was evaluated for the floating layer when titrated with $0.1 \mathrm{~N}$ potassium hydroxide with the addition of Phenolphthalein indicator to be calculated according to equation (1):

$$
\mathrm{AV}=\frac{\mathrm{ml} \text { of } \mathrm{KOH} \times \mathrm{N} \times 56.1}{\text { weight of sample }}
$$

The conversion of oleic acid can be calculated from each amount of catalyst using the acid value as shown in equation (2):

$$
\text { Conversion } \%=\frac{A V_{\text {to }}-A V_{t}}{A V_{\text {to }}} \times 100
$$

Where, (AVto) is the acid value of the reaction product at a time (0) and (AVt) represents the acid value of the reaction product at a time (t) [4] and [1].

\subsubsection{Trans-esterification of Sunflower oil}

\subsubsection{Pre-treatment of sunflower oil}

One of the important steps in transesterification reaction was to decrease the acid value to be lower than $2 \mathrm{mg}$ of potassium hydroxide per each gram. Therefore, the sunflower oil was pre-treated to be suitable for the reaction. A glass reactor was loaded with $200 \mathrm{~g}$ of the oil and preheated to $70^{\circ} \mathrm{C}$, and different ethanol to oil ratio was used $(20,25,30,35)$ as well as $1 \mathrm{wt} . \%$ of sulfuric acid was added in the reactor and the reaction continued for $30 \mathrm{~min}$. Then the mixture was transferred to a separating funnel to separate treated oil from alcohol. The top layer was alcohol acid and part of Fatty Acid Ester (FFA) and the bottom layer was the treated oil [6] [2].

\subsubsection{2 trans-esterification reaction}

Reactions of the trans-esterification were implemented using a controlled temperature $500 \mathrm{ml}$ glass reactor supplied with a stirring and condensation system. $250 \mathrm{~g}$ of pre-treated oil was loaded to the reactor and heated to the temperature of 70 to $200^{\circ} \mathrm{C}$ after that the heated ethanol and catalyst were added. After ethanolysis reaction finished; the product was left for some time in a separating funnel for 
glycerol separation then the upper layer of ethyl esters was washed with warm water and heated in a rotary evaporator to remove the access amount of ethanol.

The final amount of ethyl ester was separated and then dried using a rotary evaporation unit and weighed and the final conversion was calculated using equation (3). [6] [2].

$$
\text { conversion } \%=\frac{\text { weight of Ethyl ester }}{\text { weight of original oil }} \times 100
$$

\section{Results and discussions}

\subsection{The Esterification Reactions}

Oleic acid esterification with alcohol was carried out using a prepared HY zeolite as a catalyst. This type of reactions is classified to be a reversible reaction, thus an additional amount of ethanol was required for enhancing the reaction conversion. The esterification reaction is regulated by some factors including reaction temperature, reaction time, ethanol/ oleic acid ratio, and catalyst loading.

\subsubsection{Reaction Temperature Effect on the oleic acid conversion}

One of the reaction kinetics key factors is the reaction temperature because the rate of reaction is a temperature-dependent function under Arrhenius's law. Therefore, oleic acid esterification with ethanol takes place in the liquid phase and the targeted reaction was carried out below the boiling point of ethanol. The temperatures 60 and $70 \mathrm{oC}$ were investigated at different molar ratios for ethanol to oleic acid of (3/1,6/1, 9/1 and 12/1).

It is obvious from Figures (4.1) \& (4.2), the conversion increased from $64 \%$ to 74 $\%$ as the reaction increased from 60 to $70 \mathrm{oC}$. This effect was predicted as the temperature enables the molecular activity to be increased under the theory of collision (i.e. the need for more molecular energy could overcome the energy barrier of reaction and reacts very well). 
There is also a reason for the increased viscosity of the reactant decrease when the temperature increases which means that the molecular diffusion is increased through the internal pores of the catalyst. This leads to a quick reaction for the first 90 minutes at temperature 60 and $70^{\circ} \mathrm{C}$ within the vital sites of the catalyst. The conversion of oleic acid was subsequently decreased due to the deactivation of the zeolite HY catalyst which could be resulted from the clustering of water molecules within the catalyst's pore based on the hydrophilic nature of zeolite, thus raising the reverse reaction which led to a decrease in conversion.

Figures (1) \& (2) also show the reaction of oleic acid conversion as expected the fractional conversion increases as the reaction time rises with-molar ratio. It was found that the best maximum conversion of $77 \%$ is obtained at a 12/1 molar ratio at $70^{\circ} \mathrm{C}$, which means that reaction reaches equilibrium. All results are compatible with previous results reported in [7-10].

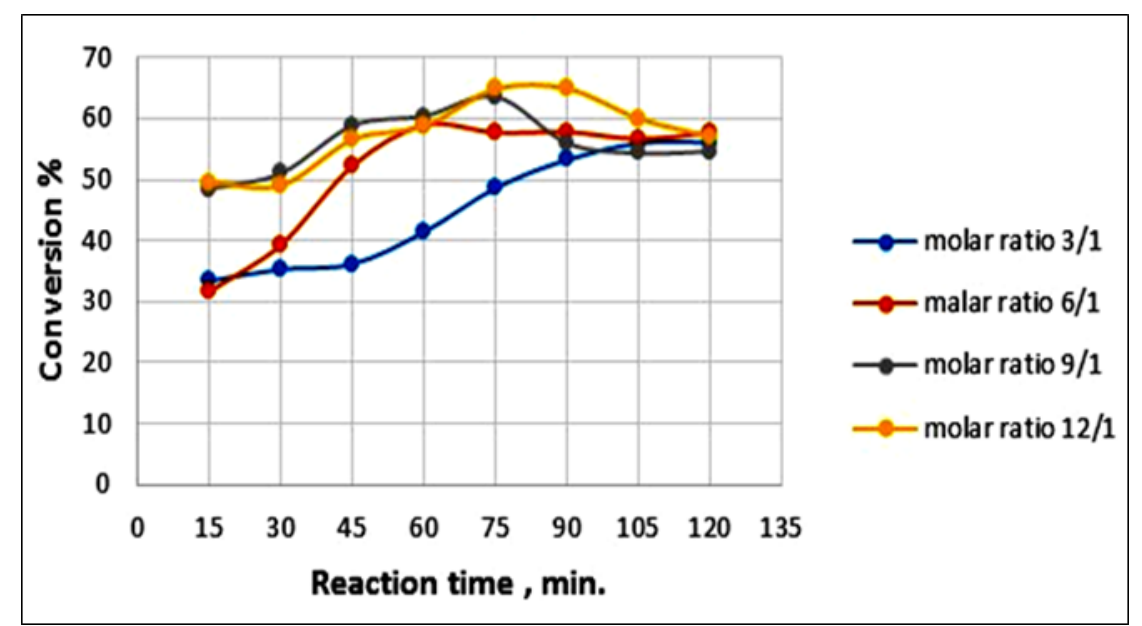

Fig. (1) Oleic acid conversion as a function of molar ratio Ethanol / Oil at $60^{\circ} \mathrm{C}$. 


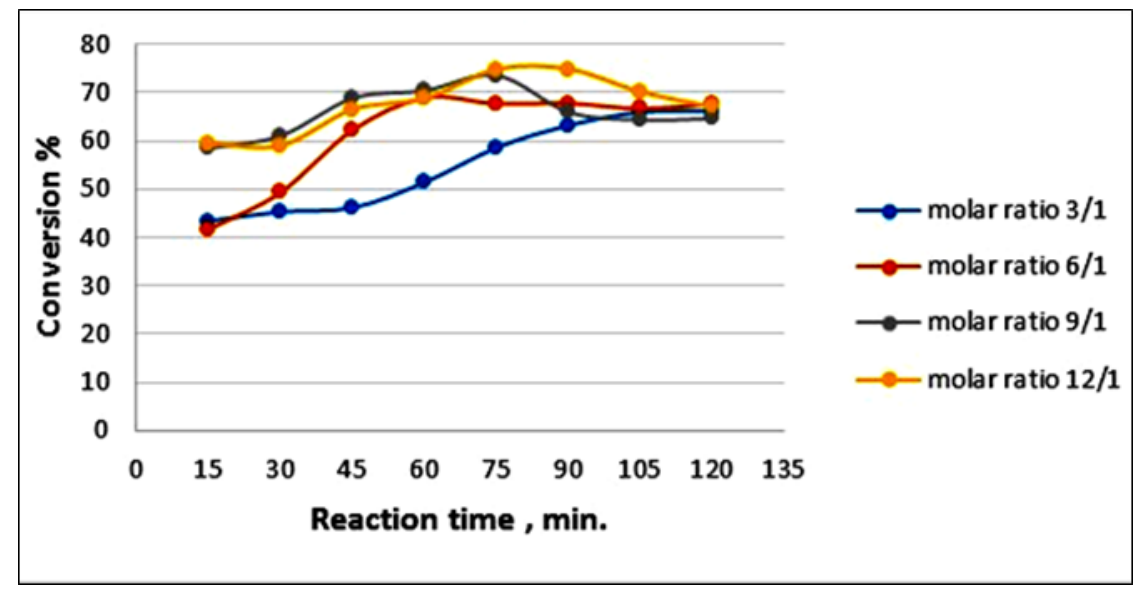

Fig. (2) Oleic acid conversion as a function of molar ratio Ethanol / Oil at $70^{\circ} \mathrm{C}$.

\subsubsection{Impact of catalyst quantity on oleic acid conversion}

In the esterification reaction of oleic acid with ethanol, the reality of weight per cent of catalyst to oil was used to test the behavior of prepared HY catalyst. Reactions were performed at a constant temperature of $70^{\circ} \mathrm{C}$ and with a fixed ratio of $12 / 1$ ethanol to oil. The effect of different weight per cent of the catalyst effect is shown in Figure (3). The best results at 5 wt. \% of the catalyst.

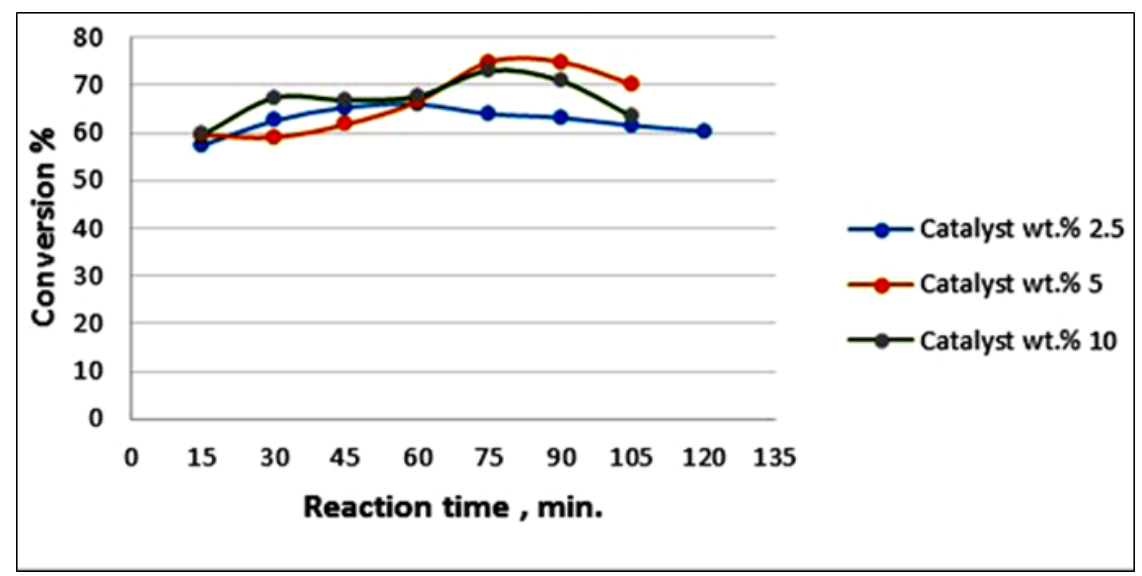

Fig. (3) Oleic acid conversion as a function of catalyst ratios

As seen in Figure (3) the esterification reaction was directly proportional to the quantity of catalyst loaded, and this issue was expected because the rise in catalyst quantity implies a rise in other active sites where the esterification reaction occurred. There is a slight increase in conversion between $5 \mathrm{wt} . \%$ and $10 \mathrm{wt} . \%$ and this not 
remarkable because at a higher amount the catalyst although of the available high surface area of the catalyst but this cause more accumulation of water on internal catalyst pores resulting from the hydrophilic properties. These observations were in strong alignment with other researches that stated that an increase in the volume of catalyst above 5 wt. \% did not affect the acid value being decreased [11], [12].

\subsubsection{Molar ratio of Ethanol / Oil influence on the conversion of oleic Acid}

The oleic acid esterification reaction with ethanol is a reversible reaction with an ethanol/oil molar stoichiometry ratio of 1:1. For improved processing, an additional quantity of ethanol is usually required. Unreacted ethanol has to be recovered and a significant amount of energy is required, so the optimum combination of energysaving and effective reaction efficiency should be calculated as effectively as possible. Four ethanol/oil molar ratios were used 3:1, 6:1, 9:1 and 12:1, with a specified $5 \mathrm{wt}$. \% catalyst and a steady $70 \mathrm{oC}$ reaction temperature. A substantial rise in oleic acid production can be observed, as seen in Figures (4) \& (5). It can be concluded that as the molar ratio rises there was a major change in oleic acid production. This excess alcohol moved the equilibrium reaction to the direction of product formation.

Another clarification is the viscosity of the reaction medium, the viscosity of the mixture decrease if the ratio increases since the viscosity of ethanol is being lower than oleic, then at high ratio (low viscosity) the effect of reactant diffusion to catalyst particles was reduced leading to increase in the reaction productivity. It can be observed in different studies and previous work, which the abroad range of the alcohol/oil ratio up to 30/1, also at a higher ratio. But it must be taken into account that at a high ratio there will be higher water and this undesirable since it reduced the final product $[3,13,14,15]$.

\subsubsection{Comparison between prepared and commercial HY Zeolite Catalyst}

Comparison between prepared and commercial HY catalyst was investigated at 5 wt. \% of catalyst and 12/1 Ethanol /oil molar ratio and the conversion was about 77 for synthesized catalyst while for the commercial catalyst is about $80 \%$ as shown in Fig.4. There was a slight increase in conversion between commercial and prepared 
catalyst due to large pore volume and higher surface area and this delayed the deactivation of the catalyst [16].

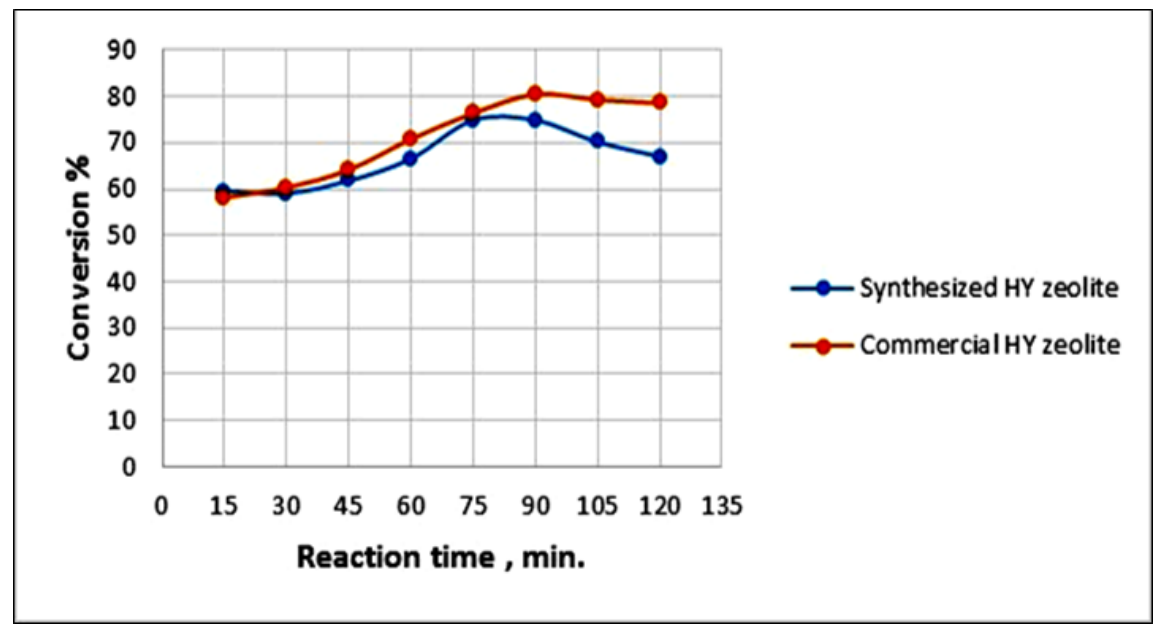

Fig. (4) Activity comparison between prepared and commercial HY zeolite at $70^{\circ} \mathrm{C}, 12 / 1$ Ethanol / Oil molar ratio.

\subsection{Transesterification Reaction}

\subsubsection{Production of Biodiesel}

Trans-esterification reaction is carried out using HY synthesized catalyst at different reaction conditions. Best biodiesel yield was about $98 \%$ obtained at $3 \mathrm{~h}$ reaction time at $200 \mathrm{o}$ C, Ethanol /oil ratio $=5$ and $5 \mathrm{wt} . \% \mathrm{HY}$ catalyst as shown in Figures (5) and (6). These results are compatible with [4] because they achieved a yield of about $92 \%$ by transesterification using $10 \mathrm{wt} . \% \mathrm{KOH}$ on $\mathrm{NaY}$ zeolite at $60^{\circ} \mathrm{C} 4 \mathrm{~h}$ and $15 / 1$ ethanol/oil ratio.

As seen in literature the sunflower oil contains four fatty acids which are palmitic acid (C16H32O2), linoleic acid (C18H32O2), oleic acid (C18H34O2), and stearic acid $(\mathrm{C} 18 \mathrm{H} 36 \mathrm{O} 2)$ so these fatty acids could convert to ester-type which is the biodiesel. The yield of biodiesel is calculated according to the following equation:

$$
\text { Yield } \%=\frac{\text { weight of biodiesel }}{\text { weight of oil used }}
$$

The transesterification of oil occurs in presence of proton $\mathrm{H}+$, and due to the transfer of proton to the oxygen atom which is double-bonded to the carbon atom, so a positive charge will be attached to the oxygen atom. Then the positive charge will 
be localized on the carbon atom and in the second step, the positive charge will be attacked by an oxygen atom of a hydroxyl group in the alcohol giving a water molecule and ester is formed [17].

So, if there is no sufficient acidity in the catalyst, the reaction in step one and formation of the carbonium ion will be weak and the above mechanism will be disturbed. Sulfonated HY catalyst considered to have good strength acidity, besides its pore volume gives rise to the diffusion of large fatty acid to react inside it producing more biodiesel. [18]. the suggested mechanism is shown in scheme 1 [19].

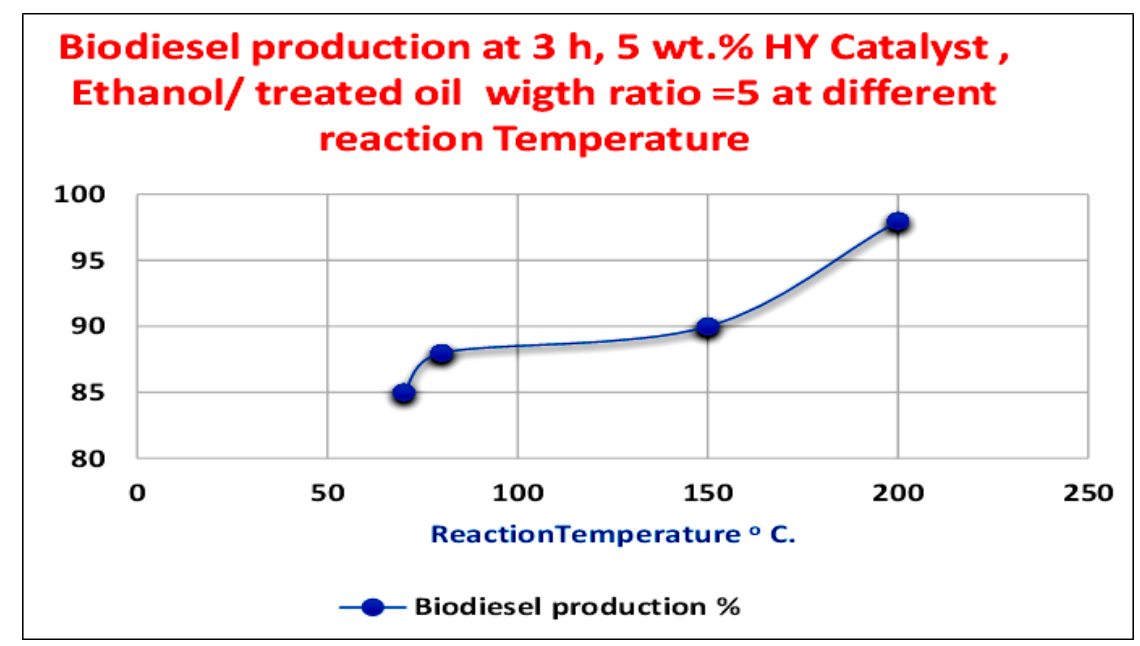

Fig. (5) Biodiesel Yield \% at different reaction temperature.

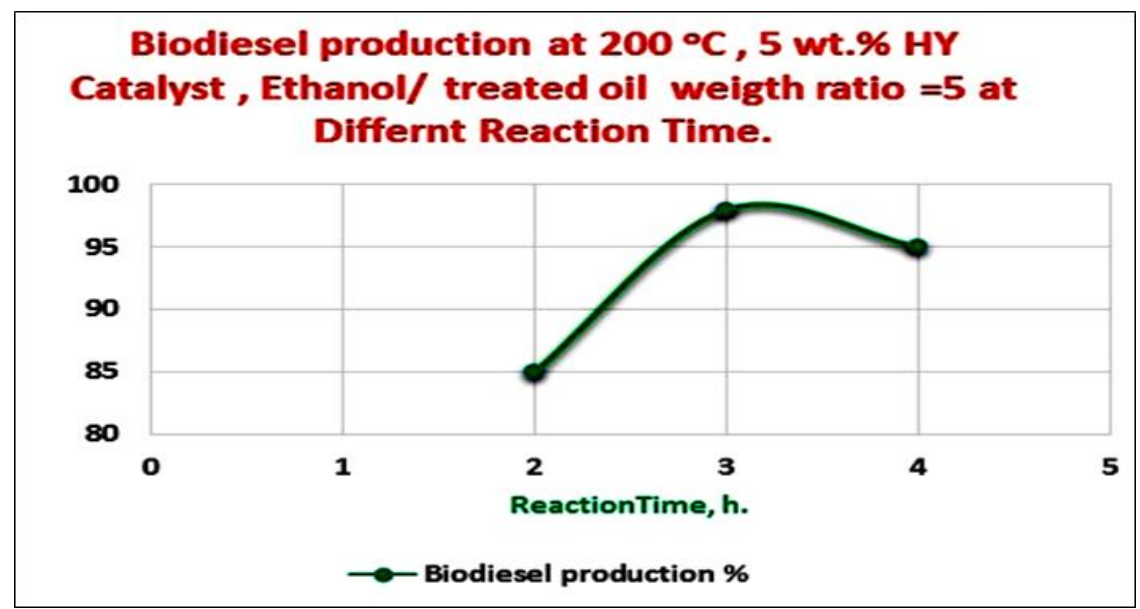

Fig. (6) Biodiesel Yield \% at different reaction time. 
Journal of Petroleum Research and Studies

Open Access
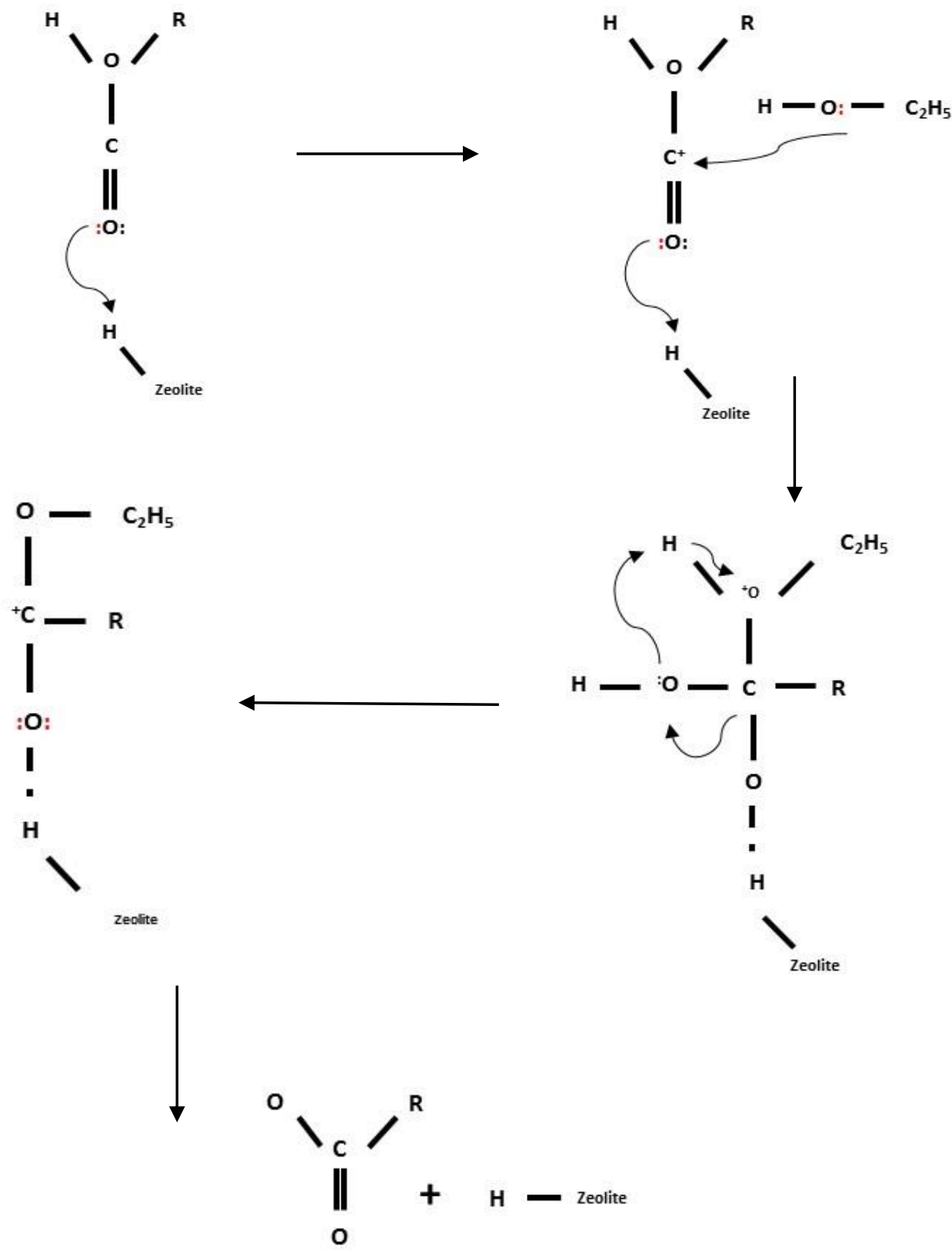

Biodiesel

Scheme. (1) Suggested mechanisms where $R=$ Alkyl group 


\subsubsection{Characterization of Biodiesel:}

The product specifications are very important since from which it can decide the validity of the produced biodiesel. The properties of prepared biodiesel are characterized using different techniques:

\subsubsection{GC -Mass, Gas Chromatography Mass Spectroscopy:}

GC-Mass spectroscopy was done on specimens of synthesized biodiesel, and the results of mass spectrum for produced was performed to investigate the ethyl ester group. The main characteristics peaks of fatty acid ester appeared by the retention time and the fragmentation pattern data.

The four peaks identified as 9-hexadecanoic acid methyl ester (C16:1), 9,12Octadecadienic acid methyl ester (C18:2), 9-Octadecanoic acid methyl ester (C18:1) and Octadecanoic acid methyl ester (C18:0) [1], [5]. Table (3) identified the composition of FAMES presents at optimum prepared biodiesel and as shown from data, the glycerol characteristics peak is present at GC -MS analysis of prepared biodiesel at a retention time of (5 to $21 \mathrm{~min}$ ).

These results confirm our selected condition and completeness of the transesterification process of triglycerides in the vegetable oil into biodiesel.

Table (3) Fatty acid ethyl ester [1].

\begin{tabular}{l|lll} 
Peak & Retention Time & Fatty Acid Ethyl Ester & Common Name \\
\hline 1 & 5.41 & C16 & Methyl palmitic \\
2 & 18.67 & C18:0 & Methyl stearate \\
3 & 20.87 & C18:1 & Methyl oelate \\
4 & 21.16 & C18:2 & Methyl linoalte
\end{tabular}

\subsubsection{TGA - Thermal Gravimetric analysis:}

TGA is an effective way to quantify the produced biodiesel due to the large temperature difference between the weight loss temperature of oil and biodiesel as shown in Figures (7) and (8). It is well known that the biodiesel starts to thermally decompose at approximately $150^{\circ} \mathrm{C}$ and continue its thermal decomposition until complete vaporization. However, the vegetable oil begins its thermal degradation at 
approximately $300^{\circ} \mathrm{C}$. Accordingly, the percentage of biodiesel conversion can be determined from weight loss as mentioned in the literature. Biodiesel vaporized completely around $330^{\circ} \mathrm{C}$ and the optimum weight loss percentage from 120 to $330^{\circ} \mathrm{C}$ as regards total weight loss was about $95 \%$.

This compatible with transesterification results. These confirm successful biodiesel production. Also, confirm previous GC-MS analysis results.

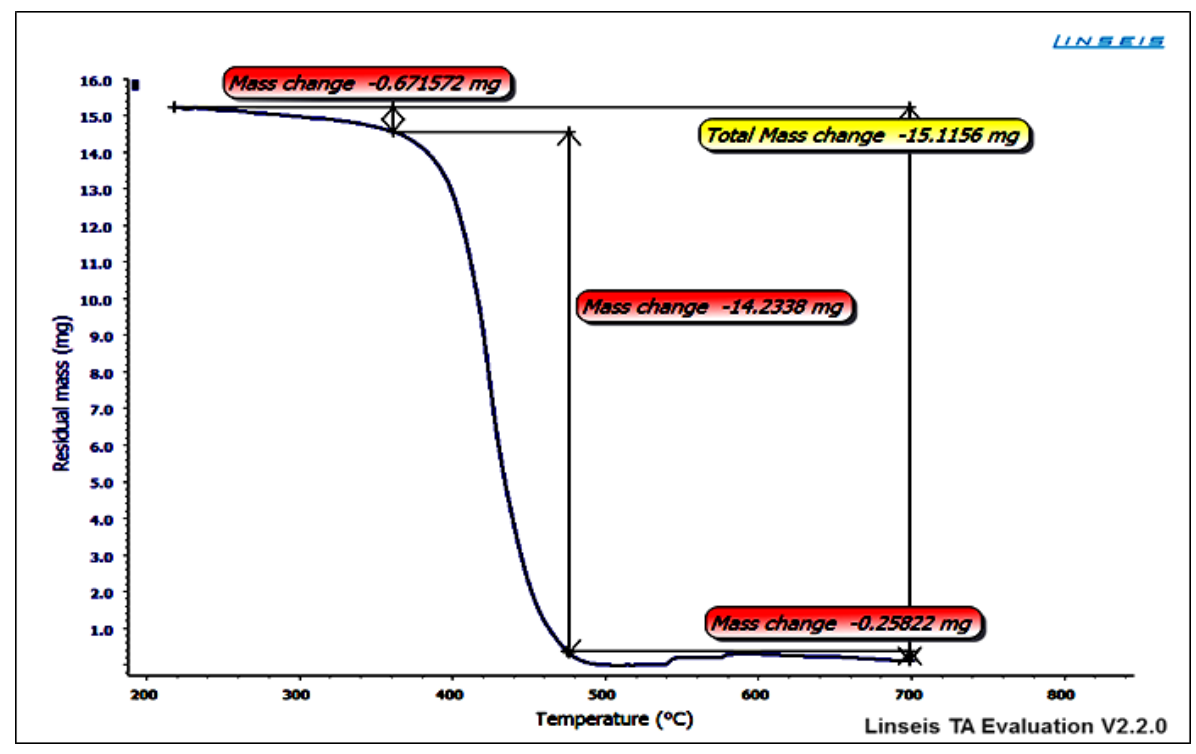

Fig. (7) TGA analysis for sun flower Oil

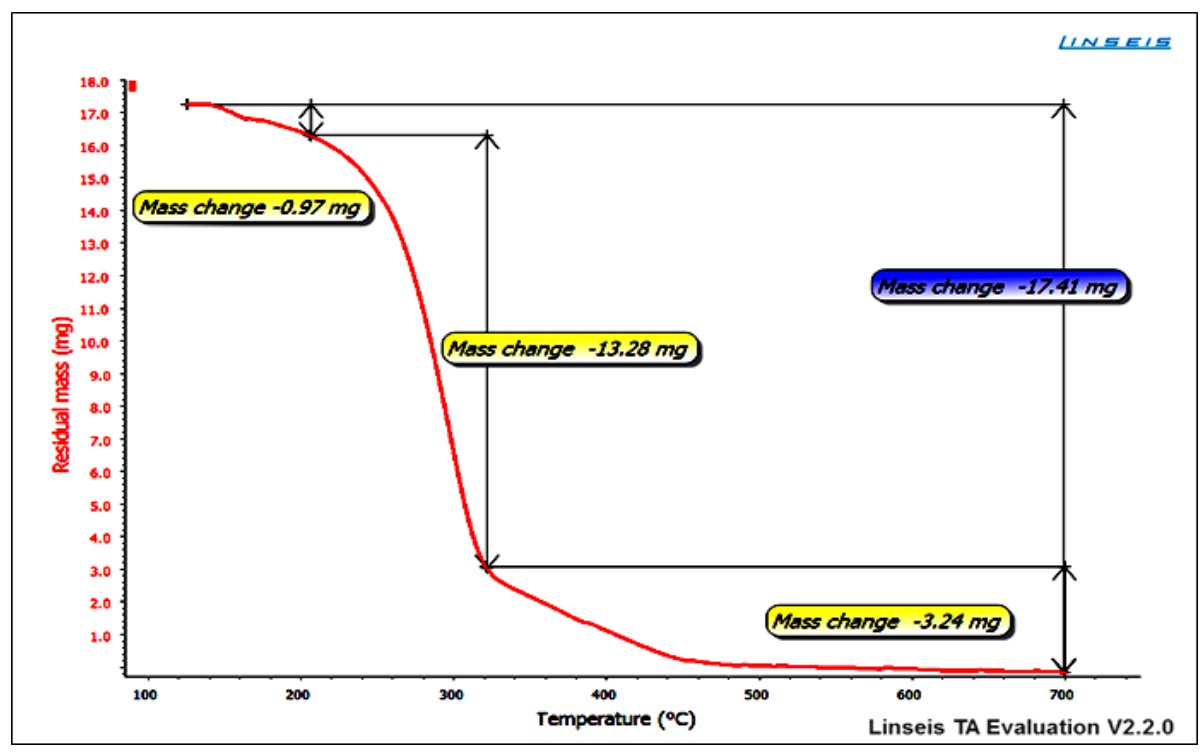

Fig. (8) TGA analysis for produced Biodiesel 


\subsubsection{FTIR Fourier Transform Infrared Spectroscopy}

Fatty esters (FAME) are quantified using FTIR. The main functional groups' present at produced biodiesel and vegetable oil. The most characteristic absorption peaks of the vegetable oil were indicated. The absorption peak appearing at $721 \mathrm{~cm}^{-1}$ is representative of $-\mathrm{CH} 2$ rocking and the other one at $1745 \mathrm{~cm}^{-1}$ is representative of $\mathrm{C}=\mathrm{O}$ ester stretch. The produced biodiesel absorption peaks appearing at $1434 \mathrm{~cm}-1$ which is the methyl ester group (CO-O-CH3) and the characterization peak at1195 $\mathrm{cm}-1$ corresponding to $(\mathrm{C}-\mathrm{O})$ ester peak. The reduction of $\mathrm{CH} 2-\mathrm{O}-$ groups in oil and the appearance of $\mathrm{CH} 3-\mathrm{O}-$ vibrations in biodiesel were obvious. Also, the split of $1163 \mathrm{~cm}^{-1}$ in the oil sample into $1195 \mathrm{~cm}^{-1}$ and $1168 \mathrm{~cm}^{-1}$ in the biodiesel sample indicates the conversion of oil into biodiesel. The main difference between the two FTIR spectrums is related to the transformation of ester groups at the oil sample into methyl esters at the produced biodiesel.

\subsubsection{Biodiesel properties:}

Produced biodiesel has different properties that characterized it. These properties are listed below:

- Flashpoint: Flashpoint (closed cup) for a synthesized sample of biodiesel was measured and the result was $120^{\circ} \mathrm{C}$, it is above the standard value of $93^{\circ} \mathrm{C}$.

- Density: Specific gravity of produced biodiesel was measured and the result was $0.886 \mathrm{~g} / \mathrm{cm}^{3}$.

- Viscosity: The measured kinematic viscosity was $5.3 \mathrm{~mm}^{2} / \mathrm{s}$ at $40^{\circ} \mathrm{C}$, which is in the range of standard mentioned above, between $1.4-6 \mathrm{~mm}^{2} / \mathrm{s}$.

- Pour point: Measured pour point was $-15^{\circ} \mathrm{C}$.

- Heating value: The heating value was $34.64 \mathrm{KJ} / \mathrm{Kg}$. 


\section{Conclusion}

HY type zeolite had been successfully prepared in our previous work by the sol-gel method under hydrothermal conditions. Synthesized HY with BET surface area of $612.83 \mathrm{~m}^{2} / \mathrm{g}$ was an active catalyst for the esterification reaction of oleic acid producing biodiesel with conversion comparable to those of commercially HY catalyst, due to the good acidity of the prepared sulfonated HY catalyst.

Transesterification reaction of sunflower oil was carried out using synthesized HY zeolite. The optimum conversion was $98 \%$ at a reaction temperature of $200^{\circ} \mathrm{C}$, Ethanol /oil ratio $=5$ and $5 \mathrm{wt}$. $\% \mathrm{HY}$ and $3 \mathrm{~h}$ reaction time, while the results proved the effectiveness of zeolite catalyst to obtain biofuels through the reaction of oleic acid esterification in the presence of ethanol, where highest conversion rate was obtained up to $78 \%$ under the reaction temperature of $70^{\circ} \mathrm{C}$. The characterization of final produced ethyl ester (biodiesel) such as density, viscosity and heating value within the acceptable range of biodiesel. the flash point was higher constituted a safety guarantee for handling and storage. 


\section{$\underline{\text { References }}$}

[1] A. Demirbas, "Biodiesel production from vegetable oils via catalytic and non-catalytic supercritical methanol transesterification methods," Progress in Energy and Combustion Science 31, vol. 31, p. 466-487, 2005.

[2] D. A., "Diesel fuel from vegetable oil via transesterifition and soap pyrolysis," Energy Sources, vol. 24, p. 835-41, 2002.

[3] M. Allen, "Straighter Than Straight Vegetable Oils," pp. 345-356, 2002.

[4] A. B. M. S. Hossain, A. N. B. A. S. and Chandran,, "Diesel Production from Waste Soyabean Oil Biomass as Renewable Energy and Environmental Recycled Process," pp. 4323-4240, 2010.

[5] M. Thirumarimurugan, V. M. S. A. M. X. D. P. and T. Kannadasan, "Preparation of Biodiesel from Sunflower Oil by Transesterification," International Journal of Bioscience, Biochemistry and Bioinformatics, Vols. Vol. 2, No. 6, 2012.

[6] B. M., "Balat M. Bio-diesel from vegetable oils via transesterification in supercritical ethanol," Energy Edu Sci Technol, vol. 16, p. 45-52, 2005.

[7] A. Kawashima, K. M. and Katsuhisa Honda, "Development of heterogeneous base catalysts for biodiesel production," Bioresource Technology, vol. 99, p. 34393443, 2008.

[8] K. BJ, M. C. Y. B. and Nowlan D., "Production of algae-based biodiesel using the continuous catalytic Mcgyan process," Bioresour Technol, vol. 102, p. 94 $100,2011$.

[9] Xie W, H. X. and Li H., "Soybean oil methyl esters preparation using NaX zeolites loaded with $\mathrm{KOH}$ as a heterogeneous catalyst," Bioresour Technol, vol. 9, p. 98:936, 2007. 
[10] Ramos MJ, C. A. R. L. R. R. and P. A. , "Transesterification of sunflower oil over zeolites using different metal loading: a case of leaching and agglomeration studies," Appl Catal A, vol. 346, pp. 79-85, 2008.

[11] Marchetti JM and Errazu AF., "Comparison of different heterogeneous catalysts and different alcohols for the esterification reaction of oleic acid," Fuel, vol. 87, p. 3477-80, 2008.

[12] J. Thomas, "Proceedings of the Royal Society A," Mathematical Physical and Engineering Science, vol. 468, p. 1884-1903, 2012.

[13] A. Demirbas, Energy Policy, vol. 35, p. 4661-4670., 2007.

[14] G. Knothe, Top. Catal., vol. 53, p. 714-720, 2010.

[15] A. F. Lee, J. A. B. J. C. M. and Karen Wilson, "Heterogeneous catalysis for sustainable biodiesel production via esterification and transesterification," Chem. Soc. Rev, vol. 43, pp. 7887--7916 |, 2014.

[16] M. D. Serio, R. T. L. P. and Elio Santacesaria, "Heterogeneous Catalysts for Biodiesel Production," Energy \& Fuels 2008, 22, 207-217, vol. 22, pp. 207-217, 2008.

[17] A. S. Chouhan and A.K. Sarma, "Modern heterogeneous catalysts for biodiesel production," Renewable and Sustainable Energy Reviews, vol. 15, p. 4378-4399, 2011.

[18] Marra F and Hanna MA, "Biodiesel production: a review," Bioresour Technol, vol. 70, pp. 1-15, 1999.

[19] L. Meher, D. V. S. and S.N. Naik, "Technical aspects of biodiesel production by transesterification - a review," Renewable and Sustainable Energy Reviews, vol. 1, pp. 1-21, 2004.

[20] J. Marchetti, V. M. and A.F. Errazu, "Possible methods for biodiesel production," Renewable and Sustainable Energy Reviews, vol. 11, pp. 1300-1311, 2007. 
[21] D. Y. Leung, X. W. and M.K.H. Leung, "A review on biodiesel production using catalyzed transesterification," Applied Energy, vol. 87, pp. 1083-1095, 2010.

[22] I. L. Lucena, G. F. S. and Fabiano A. N. Fernandes, "Biodiesel Production by Esterification of Oleic Acid with Methanol Using a Water Adsorption Apparatus," Ind. Eng. Chem. Res., vol. 47, p. 6885-6889, 2008.

[23] A. Brito, M. E. B. and N. Otero, "Zeolite Y as a Heterogeneous Catalyst in Biodiesel Fuel Production from Used Vegetable Oil," Energy \& Fuels , vol. 21, pp. 3280-3283, 2007.

[24] N. Diamantopoulos, D. Panagiotaras and D. Nikolopoulos, Comprehensive Review on the Biodiesel Production using Solid Acid Heterogeneous Catalysts, vol. 1, J Thermodyn Cata, 2015. 